\title{
A Study on Uric Acid Levels in Non Diabetic Patients at a Tertiary Care Hospital
}

\author{
Vishwanath VN', Vijaya Mohan ${ }^{1}$ \\ ${ }^{1}$ Associate Professor, Department of General Medicine, KBNIMS, Gulbarga, Karnataka.
}

\section{Abstract}

Background: The pathophysiology of diabetic nephropathy is complex and still not fully elucidated. Observational studies suggest a relationship of UA level with incident CKD, but studies evaluating the relationship with decline in kidney function in established CKD are conflictingSeveral prospective studies have suggested that hyperuricemia is associated with an increased risk of incident cardiovascular events and death in both nondiabetic and type 2 diabetic individuals Hyperuricemia also is largely prevalent in patients with chronic kidney disease(CKD). Subjects and Methods: The patients were randomly divided into two groups according group chosen by time of enrollment. By using simple random method, 64 study subjects will be taken, and the study subject is divided into 2 groups. A detailed history, anthropometry, vital signs, clinical examination and laboratory parameters were recorded for both the study group. Results: The Study reveals that, there was no statistical significant difference of mean serum uric acid among smokers and non-smokers in non-diabetes patients with CKD ( $>>0.05)$. Study reveals that, there was no statistical significant difference of mean serum uric acid among alcoholic and non-alcoholic cases in non-diabetes patients with CKD $(\mathrm{P}>0.05)$. Conclusion: non-diabetic patients with CKD cases $(\mathrm{P}<0.05)$. There was an increasing trend in the mean serum creatinine concentration with a corresponding decreasing trend in eGFR across increasing UA categories There is significantly sloping down of GFR with increase of SUA level as model.

Keywords: Hyperuricemia, Nondiabetic, Creatinine.

Corresponding Author: Dr. Vijaya Mohan, Associate Professor, Department of General Medicine, KBNIMS, Gulbarga, Karnataka.

Received: December 2019

Accepted: December 2019

\section{Introduction}

Uric acid is the final product of purine metabolism in humans. Purines, compounds that are vital components of nucleic acid and coenzymes, may be synthesized in the body or they may be obtained by ingesting food rich in nucleic material (e.g. Liver, sweetbread etc.). It is an important antioxidant at its normal reference interval, which contributes significantly to total anti-oxidant capacity of serum. It acts paradoxically at higher levels, i.e. when above $6 \mathrm{mg} / \mathrm{dl}$ in females and more than $6.5-7 \mathrm{mg} / \mathrm{dl}$ in men, uric acid acts like pro-oxidant. It has therapeutic role as antioxidant, but can be a marker of oxidative stress as well.There is slight variation in level of serum uric acid between males to females. ${ }^{[1]}$

As uric acid is a known anti-oxidant, it has a beneficial role in diseases.But it has been found that elevated levels of uric acid are associated with high risks of cerebrovascular complication of type 2 diabetes mellitus. Studies have reported a strong association between elevated uric acid levels and obesity, metabolic syndrome, diabetes mellitus, hypertension, cardiovascular and renal disorders. ${ }^{[2]}$

Decline in uric acid levels have been reported in type 2DM in several studies.However contradictory reports are also available with elevated uric acid levels There are a few reports available which study the role of uric acid in diabetic nephropathy. ${ }^{[3]}$

The tide of type 2 diabetes is rising in the U.S. and all over the world, thereby becoming an increasingly powerful threat to global health. Type 2 diabetes also has become the leading cause of end-stage renal disease in the world, and the number of patients diagnosed each year with end-stage renal disease attributed to type 2 diabetes is rising.

The pathophysiology of diabetic nephropathy is complex and still not fully elucidated. Observational studies suggest a relationship of UA level with incident CKD, but studies evaluating the relationship with decline in kidney function in established CKD are conflicting Several prospective studies have suggested that hyperuricemia is associated with an increased risk of incident cardiovascular events and death in both nondiabetic and type 2diabetic individuals Hyperuricemia also is largely prevalent in patients with chronickidney disease(CKD). ${ }^{[4]}$

However, hyperuricemia might have a pathogenic role in the development and progression of CKD, rather than solely reflecting decreased renal uric acid excretion. Indeed, several.

An objective of our study is to compare uric acid levels in type 2 DM patients with renal disease as compared to nondiabetic controls. We also aim to compare its levels among patients in different stages of diabetic nephropathy. To our 
knowledge, however, no large prospective studies are available on the relationship between hyperuricemia and incident CKD in patients with type 2 diabetes and normal or near-normal kidney function. Thus, the purpose of this prospective, observational study was to determine whether baseline serum uric acid levels are associated with an increased incidence of CKD in a large cohort of type 2 diabetic patients with preserved kidney function at baseline and without a previous history of cardiovascular disease.

Uric acid (UA) is consistently overproduced by ischemic tissues and has been associated with endothelial dysfunction by inhibiting nitric oxide release. Hence it was hypothesized that Uric acid and/or its precursors might serve as injury signals in renal ischemia. Serum uric acid level was also strongly associated with microalbuminuria and reduced glomerular filtration rate in renal diseases.

\section{Subjects and Methods}

Sample size $(n)=64$ were divided in to two groups study and controls each 32 samples

Calculation of sample size

Sample size $(\mathrm{n})=\mathrm{Z}^{2} \mathrm{PQ} / \mathrm{L}^{2}$

Where $\mathrm{n}=$ Sample size

$\mathrm{Z} \alpha=1.96$ for $5 \%$ significant level

$\mathrm{P}=$ Prevalence rate of chronic kidney disease was $16.6 \% 188$

$\mathrm{Q}=100-16.6=100-16.6=83.4$

$\mathrm{L}=$ permissible error of $\mathrm{P}$

$=55 \%$ of $\mathrm{P}=9.13$

Sample size $(\mathrm{n})=(1.96) \times 29.7 \times 70.3 /(5.31)$

$=63.77$

Study Size: 64

The patients were randomly divided into two groups according group chosen by time of enrollment. By using simple random method, 64 study subjects will be taken, and the study subject is divided into following 2 groups:

Group 1: Comprised of 32 cases suffering from type 2 diabetes mellitus.

Group 2: Comprised of 32 controls not suffering from type 2 diabetes mellitus.

A detailed history, anthropometry, vital signs, clinical examination and laboratory parameters were recorded for both the study group.

\section{Results}

Table 1: Comparison of serum uric acid among smokers and alcoholics in non-diabetic patients with CKD

\begin{tabular}{|c|c|c|c|}
\hline \multirow{2}{*}{ Variables } & Serum uric acid & t- test values & $\begin{array}{c}\text { P-value\& } \\
\text { significance }\end{array}$ \\
\cline { 2 - 2 } & Mean \pm SD & & \\
\hline Smokers (N=9) & $10.2 \pm 3.35$ & $\mathrm{t}=1.981$ & $\mathrm{P}=0.062, \mathrm{NS}$ \\
\hline $\begin{array}{c}\text { Nonsmokers } \\
(\mathrm{N}=23)\end{array}$ & $7.98 \pm 2.42$ & & \\
\hline $\begin{array}{c}\text { Alcoholic(N=13) } \\
\text { Nonalcoholic } \\
(\mathrm{N}=19)\end{array}$ & $8.49 \pm 2.15$ & $\mathrm{t}=0.253$ & $\mathrm{P}=0.802, \mathrm{NS}$ \\
\hline
\end{tabular}

The Study reveals that, there was no statistical significant difference of mean serum uric acidamong smokers and nonsmokers in non-diabetes patients with CKD $(\mathrm{P}>0.05)$.Study revealsthat, there was no statistical significant difference of mean serum uric acid among alcoholic andnon-alcoholic cases in non-diabetes patients with CKD $(\mathrm{P}>0.05)$.

\begin{tabular}{|c|c|c|c|c|c|}
\hline \multirow{3}{*}{ Variables } & \multicolumn{4}{|c|}{ Serum Uric Acid levels (mg/dL) } & \multirow{3}{*}{$\begin{array}{l}\text { ANOVA- } \\
\text { test P-value } \\
\& \\
\text { significance }\end{array}$} \\
\hline & $<6$ & 6-8 & $8-10$ & $>10$ & \\
\hline & $\begin{array}{l}\text { Mean } \pm \\
\text { SD }\end{array}$ & $\begin{array}{l}\text { Mean } \pm \\
\text { SD }\end{array}$ & $\begin{array}{l}\text { Mean } \pm \\
\text { SD }\end{array}$ & $\begin{array}{l}\text { Mean } \pm \\
\text { SD }\end{array}$ & \\
\hline Age (years) & $\begin{array}{l}41.5 \pm \\
12.97\end{array}$ & $\begin{array}{l}45.54 \pm \\
13.02\end{array}$ & $\begin{array}{c}38.33 \pm \\
13.2\end{array}$ & $\begin{array}{c}32.37 \pm \\
11.95\end{array}$ & $\begin{array}{c}\mathrm{F}=1.479 \\
\mathrm{P}=0.242 \\
\mathrm{NS}\end{array}$ \\
\hline $\begin{array}{l}\text { Body mass } \\
\text { index } \\
(\mathrm{kg} / \mathrm{m} 2) \mathrm{BMI}\end{array}$ & $\begin{array}{c}26.17 \pm \\
4.28\end{array}$ & $\begin{array}{c}27.05 \pm \\
3.95\end{array}$ & $\begin{array}{c}27.48 \pm \\
2.29\end{array}$ & $\begin{array}{c}28.20 \pm \\
3.43\end{array}$ & $\begin{array}{c}\mathrm{F}=0.315 \\
\mathrm{P}=0.815 \\
\mathrm{NS}\end{array}$ \\
\hline $\begin{array}{c}\text { Serum creatinine } \\
(\mathrm{mg} / \mathrm{dL})\end{array}$ & $1.51 \pm 0.21$ & $2.63 \pm 2.18$ & $\begin{array}{c}3.79 \pm \\
3.38\end{array}$ & $5.57 \pm 3.56$ & $\begin{array}{c}F=2.98 \\
P=0.037, S\end{array}$ \\
\hline \begin{tabular}{c|c|} 
eGFR \\
$(\mathrm{ml} / \mathrm{min} / 1.73 \mathrm{~m} 2)$
\end{tabular} & $\begin{array}{c}73.75 \pm \\
11.44\end{array}$ & $\begin{array}{c}50.47 \pm \\
26.26 \\
\end{array}$ & $\begin{array}{l}54.11 \pm \\
207 \\
\end{array}$ & $\begin{array}{c}29.37 \pm \\
20.23 \\
\end{array}$ & $\begin{array}{c}\mathrm{F}=3.57 \\
\mathrm{P}=0.026, \mathrm{~S}\end{array}$ \\
\hline Total count $(\mathrm{TC})$ & $11.2 \pm 4.37$ & $79.62 \pm 4.25$ & $\begin{array}{l}9.93 \pm \\
6.52\end{array}$ & $\begin{array}{l}11.43 \pm \\
11.23\end{array}$ & $\begin{array}{c}\mathrm{F}=0.106 \\
\mathrm{P}=0.955 \\
\mathrm{NS}\end{array}$ \\
\hline $\mathrm{HB}(\mathrm{g} / \mathrm{dl})$ & $\begin{array}{c}10.30 \pm \\
2.24\end{array}$ & $8.02 \pm 1.86$ & $\begin{array}{c}8.75 \pm \\
1.77\end{array}$ & $7.87 \pm 1.12$ & \begin{tabular}{|c}
$\mathrm{F}=1.94$ \\
$\mathrm{P}=0.145$ \\
$\mathrm{NS}$
\end{tabular} \\
\hline \begin{tabular}{|c|} 
Total cholesterol \\
$(\mathrm{mg} / \mathrm{dL})$
\end{tabular} & $\begin{array}{c}181.5 \pm \\
13.12\end{array}$ & $\begin{array}{l}198.0 \pm \\
10.46\end{array}$ & $\begin{array}{c}202.55 \pm \\
20.07\end{array}$ & $\begin{array}{c}203.53 \pm \\
20.22\end{array}$ & $\begin{array}{c}\mathrm{F}=1.63 \\
\mathrm{P}=0.205 \\
\mathrm{NS}\end{array}$ \\
\hline $\begin{array}{l}\text { Triglycerides } \\
\text { (mg/dL) }\end{array}$ & $\begin{array}{c}188.5 \pm \\
10.78\end{array}$ & $\begin{array}{c}207.81 \pm \\
14.45\end{array}$ & $\begin{array}{l}196.11 \pm \\
14.92\end{array}$ & $\begin{array}{c}199.62 \pm \\
27.05\end{array}$ & $\begin{array}{c}\mathrm{F}=1.189 \\
\mathrm{P}=0.332 \\
\mathrm{NS}\end{array}$ \\
\hline
\end{tabular}

The Study reveals that, there was no statistical significant difference of mean age, BMI,TC, HB, total cholesterol and triglycerides in the levels of serum uric acid in non-diabetic patients with CKD cases $(\mathrm{P}>0.05)$.There was statistical significant difference of Ser. Creatinine and GFR in the levels of serum uric acid in non-diabetic patients with CKD cases $(\mathrm{P}<0.05)$. There was an increasing trend in the mean serum creatinine concentration with a corresponding decreasing trend in eGFR across increasing UA categories There is significantly sloping down of GFR with increase of SUA level as model.

Table 3: Distribution of cases according to serum uric acid levels in CKD cases

\begin{tabular}{|l|l|l|l|l|}
\hline $\begin{array}{l}\text { Serum uric } \\
\text { acid Levels }\end{array}$ & \multicolumn{2}{l|}{$\begin{array}{l}\text { Non-diabetic patients } \\
\text { with CKD }\end{array}$} & Total \\
\hline & No. & $\%$ & No. & $\%$ \\
\hline$<6$ & 4 & 12.5 & 10 & 15.6 \\
\hline $6-8$ & 11 & 34.4 & 17 & 26.6 \\
\hline $8-10$ & 9 & 28.1 & 16 & 25.0 \\
\hline$>10$ & 8 & 25.0 & 21 & 32.8 \\
\hline Total & 32 & 100.0 & 64 & 100.0 \\
\hline
\end{tabular}

\section{Discussion}

The kidneys play an important role in the maintenance of normal body function. The basic function of the kidneys has to do with the formation of urine through complex filtration, reabsorption and secretion mechanisms. In addition, the kidneys also excrete urea and uric acid which are the end products of protein and nucleic acid metabolism.

The kidneys regulate fluid, electrolyte and acid base balance of the body and create a steady environment for the metabolic processes of tissues and cells. This function is essentialrealized by balancing solute and water transport, 
excreting metabolic waste products, conserving nutrients, and regulating acid-base balance in the body.

Additionally, the kidney also produces three important hormones; erythropoietin which stimulates the production of red blood cells, renin which regulates blood pressure and calcitriol (the active form of vitamin D) which helps in regulation of plasma calcium levels.

Kidney disease results in the loss or reduction of functioning nephrons. Chronic kidney disease (CKD) a new terminology that has replaced chronic renal failure (CRF) was defined in 2002 by the National Kidney Foundation Kidney Disease Quality Outcome Initiative (NKF/KDOQI) as structural damage or GFR $<60 \mathrm{ml} / \mathrm{min} / 1.73 \mathrm{~m} 2$ for more than three months. Kidney damage is defined by the NKF/KDOQI as pathological abnormalities or markers of kidney damage, including abnormalities in urine or blood tests or abnormal imaging tests. ${ }^{[5]}$

This new vocabulary provides a platform for healthcare professionals tasked with caring for CKD patients worldwide to speak a common language. In addition, it gives a simple definition of CKD and a staging system which distinguishes groups of patients. ${ }^{[6]}$

Clinical and epidemiological reports have provided a relationship between numerous factors and the initiation and progression of CKD. These have been grouped into two well defined classes: those that cause the CKD (risk factors) and those that are associated with CKD in the absence of established causal relations (risk markers).

It is important to identify factors that increase the risk for CKD, even in individuals with normal GFR. Risk factors include small for gestation birth weight, childhood obesity, hypertension, diabetes mellitus, autoimmune disease, advanced age, African ancestry, a family history of kidney disease, a previous episode of acute kidney injury, and the presence of proteinuria, abnormal urinary sediment, or structural abnormalities of the urinary tract. Many rare inherited forms of CKD follow a Mendelian inheritance pattern, often as part of a systemic syndrome, with the most common in this category being autosomal dominant polycystic kidney disease. In addition, recent research in the genetics of predisposition to common complex diseases has revealed DNA sequence variants at a number of genetic locithat are associated with common forms of CKD. A striking example is the finding of allelic versions of the APOL1 gene, of West African population ancestry, which contributes to the several-fold higher frequency of certain common etiologies of nondiabetic CKD (e.g., focal segmental glomerulosclerosis) observed among African and Hispanic Americans. The prevalence in West African populations seems to have arisen as an evolutionary adaptation conferring protection from tropical pathogens. As in other common diseaseswith a heritable component, an environmental trigger (such as a viral pathogen) is required to transform genetic risk into disease. ${ }^{[7]}$

To stage CKD, it is necessary to estimate the GFR rather than relying on serum creatinine concentration (Table below). Many laboratories now report an estimated GFR, or eGFR, using one of these equations.

The normal annual mean decline in GFR with age from the peak GFR $(\sim 120 \mathrm{~mL} / \mathrm{min}$ per $1.73 \mathrm{~m} 2)$ attained during the third decade of life is $\sim 1 \mathrm{~mL} / \mathrm{min}$ per year per $1.73 \mathrm{~m} 2$, reaching a mean value of $70 \mathrm{~mL} / \mathrm{min}$ per $1.73 \mathrm{~m} 2$ at age 70 .
Although reduced GFR occurs with human aging, the lower GFR signifies a true loss of kidney function, with all of the implications that apply to the corresponding stage of CKD. The mean GFR is lower in women than in men. For example, a woman in her 80 s with a normal serum creatinine may have a GFR of just $50 \mathrm{~mL} / \mathrm{min}$ per $1.73 \mathrm{~m} 2$.

Mean uric acid level in subjects with normal total cholesterol $(<200 \mathrm{mg} / \mathrm{dl})$, borderline high $(200-239 \mathrm{mg} / \mathrm{dl})$ and high total cholesterol $(\geq 240 \mathrm{mg} / \mathrm{dl})$ was $<8 \mathrm{mg} / \mathrm{dl}, 8-10 \mathrm{mg} / \mathrm{dl}$ and $>10$ $\mathrm{mg} / \mathrm{dl}$ ). Mean value of SUA increased with the increase in total cholesterol level. There was statistical significant difference of total cholesterol and triglycerides in the levels of serum uric acid in Type 2 diabetes mellitus with CKD cases $(\mathrm{P}<0.05)$ in group2 and non-significant in group1. That is Total cholesterol remains higher side when we compare with uric acid levels though statistically showing nonsignificant in group1.That strong association between dyslipidemia and SUA present. In an another study strong correlation between dyslipidemia and SUA levels .Sathiya, R et al. shows significant increase in serum total cholesterol levels and level of SUA. ${ }^{[8]}$

In all CKD non-diabetic and diabetic subjects, mean uric acid level with different GFR levels and was shows respectively with a $\mathrm{P}$ value of $<0.001$.In our study patients with GFR and serum uric acid level are inverse ratios. GFR less than $30 \mathrm{~mL} / \mathrm{min} / 1.73 \mathrm{~m}^{2}$ have higher SUA levels and patients with GFR more than $70 \mathrm{~mL} / \mathrm{min} / 1.73 \mathrm{~m}^{2}$ have near to normal values. Several prospective studies have suggested that hyperuricemia is associated with an increased risk of incident cardiovascular events and death in both nondiabetic and type 2 diabetic individuals. ${ }^{[9]}$

Hyperuricemia also is largely prevalent in patients with chronic kidney disease (CKD) . Indeed, several, but not all as tables above, prospective studies recently have shown a significant association between hyperuricemia and adverse renal outcomes in both the general population and other nondiabetic high-risk patient populations. However, prospective data on the relationship between hyperuricemia and adverse renal outcomes in patients with type 2 diabetes are scarce. In two study 1,342 patients with type 2 diabetes and CKD participating in the RENAAL trial, Miao et al. ${ }^{10}$ reported that losartan lowered serum uric acid by $0.16 \mathrm{mg} / \mathrm{dL}(\mathrm{P}=$ 0.031) compared with placebo during the first 6 months and that the risk of renal events, defined as a doubling of serum creatinine or end-stage renal disease, wassignificantly decreased by $6 \%$ per $0.5 \mathrm{mg} / \mathrm{dL}$ decrement in uric acid. This effect was independent of other risk markers, including eGFR and albuminuria. The authors concluded that a part of the losartan's renoprotective effect could be attributed to its effect on serum uric acid.

\section{Conclusion}

The Study reveals that, there was no statistical significant difference of mean age, BMI,TC, HB, total cholesterol and triglycerides in the levels of serum uric acid in non-diabetic patients with CKD cases.

\section{References}

1. William S. Waring and ShahanaEsmail. How Should Serum Uric Acid Concentrations be interpreted in Patients with Hypertension? 
Vishwanath od Mahan: A Study an Uric Acid Levels in Nan Dialeetic Patients at a Jertiary Care Haspital

Current Hypertension Reviews, 2005, 1, 89-95.

2. Richard J. Johnson, Duk-Hee Kang, Daniel Feig, Salah Kivlighn, John Kanellis, Susumu Watanabe, et al. Is There a Pathogenetic Role for Uric Acid in Hypertension and Cardiovascular and Renal Disease? Hypertension. 2003; 41:1183-1190.

3. Melvin R Hayden and Suresh C Tyagi. Uric acid: A new look at an old risk marker forcardiovascular disease, metabolic syndrome, and type 2 diabetes mellitus: The urate redox shuttle. Nutrition \& Metabolism 2004, 1:10

4. Berne M. The role of adenosine in the regulation of coronary blood flow. Circulation Res, 1980; 47:807-13.

5. NKF/DOQITM N.K.F. (2002) Clinical practice guidelines for chronic kidney disease.American Journal of Kidney Diseases, S1 - S266.

6. Levin A. (2003) The advantage of a uniform terminology and staging system for chronic kidney disease (CKD). Nephrol Dial Transplant
$18,1446-1451$

7. Joanne Bargman, Karl Skorecki. Harrison's principle of Internal medicine, 19th Edition, Chapter 335 Chronic Kidney Didease, p 1811.).

8. Sathiya, R et al. "A Comparative Study of Serum Uric Acid levels and Lipid Ratios in Coronary Artery Disease Patients" International journal of biomedical science : IJBS vol. 10,2 (2014): 124-8.

9. Fang J, Alderman MH. Serum uric acid and cardiovascular mortality the NHANES I epidemiologic follow-up study, 1971-1992:National Health and Nutrition Examination Survey. JAMA 2000;283:24042410 .

10. Anupama YJ, Uma G. Prevalence of chronic kidney disease among adults in a rural community in South India: Results from the kidney disease screening (KIDS) project. Indian J Nephrol. 2014;24(4):21421.

Copyright: () the author(s), 2019. It is an open-access article distributed under the terms of the Creative Commons Attribution License (CC BY 4.0), which permits authors to retain ownership of the copyright for their content, and allow anyone to download, reuse, reprint, modify, distribute and/or copy the content as long as the original authors and source are cited.

How to cite this article: Vishwanath VN, Mohan V. A Study on Uric Acid Levels in Non Diabetic Patients at a Tertiary Care Hospital. Acad. J Med. 2019;2(2):171-74.

DOI: dx.doi.org/10.21276/ajm.2019.2.2.44

Source of Support: Nil, Conflict of Interest: None declared. 